\section{Alcidentes COM MATERIAL BIOLÓGico \\ POTENCIALMENTE CONTAMINADO, ENVOLVENDO A EQUIPE DE SAÚDE DE UM MUNICÍPIO DO INTERIOR PAULISTA}

Nayara Frais de Andrade* Renata Karina Reis**

\section{Introdução}

Os trabalhadores de enfermagem, durante a assistência aos pacientes, estão expostos a inúmeros riscos ocupacionais causados por fatores químicos (drogas citostáticas, quimioterápicos, formaldeído, gases), físicos (referentes ao ambiente de trabalho: temperatura, radiação, iluminação, ruídos), mecânicos (queda no manuseio), biológicos (vírus, bactérias), ergonômicos (inadequação dos equipamentos) e psicossociais (cansaço, estresse, sobrecarga de trabalho), que podem ocasionar doenças ocupacionais e acidentes de trabalho (MARZIALE, RODRIGUES, 2002).

Segundo Rezende (2003), risco ocupacional é todo fator ambiental que pode ocasionar lesão, doença ou inaptidão ou afetar o bem-estar dos trabalhadores.

Os riscos também podem ser classificados de acordo com a responsabilidade: real, suposto e tecidual. Real quando a responsabilidade recai sobre o empregador; suposto quando se entende que o profissional conhece as causas que favorecem o risco e residual quando o responsável é o próprio trabalhador (MARINHO et al., 2004).

Neste trabalho, serão enfatizados os riscos biológicos, que são os principais riscos existentes entre os profissionais da área da saúde e que, segundo Marziale e Rodrigues (2002), referem-se ao contato do trabalhador com microorganismos (principalmente vírus e bactérias) ou material infectocontagioso, os quais podem causar diversas doenças.

*Aluna do curso de Enfermagem do Centro Universitário de Araraquara: andrade.nayara@gmail.com ** Professora Mestre do Centro Universitário de Araraquara: rkreis@uniara.com.br
Esse contato se dá por meio de microorganismos patológicos oriundos de acidentes ocasionados pela manipulação de material perfurocortante, contato com sangue e fluídos orgânicos no ambiente, através de agulhas ou objetos cortantes, ou contato com a pele e/ou mucosa.

Com o surgimento da Síndrome da Imunodeficiência Adquirida (AIDS), maior ênfase passou a ser dada à exposição desses trabalhadores ao sangue. Em um estudo realizado no Brasil, com trabalhadores da saúde, visando a identificação do risco ocupacional de infecção pelo vírus HIV, foi constatado que $88,8 \%$ dos acidentes de trabalho notificados acometeram o pessoal da enfermagem (MARZIALE, RODRIGUES, 2002).

Ao pensar em doenças infectocontagiosas, é provável que a AIDS seja a primeira a ser lembrada e temida. Porém, muitas outras doenças, que infectam milhares de pessoas, também devem ser lembradas. Entre elas, as hepatites B e C.

Apesar da AIDS ter maior impacto, o risco de contaminação com hepatite B é mais preocupante. Existe uma maior probabilidade de contágio quando ocorre um acidente com sangue contaminado com o vírus da hepatite B (HBV), em torno de $6 \%$ a $40 \%$, do que a transmissão do HIV, que varia de $0,3 \%$ a $0,5 \%$, e a do HVC, de $2 \%$ a $10 \%$. Isso ocorre porque a quantidade de partículas virais do HBV normalmente é maior e o vírus é resistente. Lembrando que fatores como a gravidade, tamanho da lesão, presença e volume de sangue envolvido, condições clínicas do paciente-fonte e seguimento adequado pósexposição interferem no risco. (MARINHO et al., 2005).

Outra preocupação, de acordo com Braga (2000), é o fato desses profissionais não darem importância às pequenas lesões, tais como a picada de agulha, levando então à subnotificação.

A subnotificação dos acidentes no Brasil dificulta em demasia o aumento de pesquisas sobre o assunto e, principalmente, nas ações sobre o problema. Em sua pesquisa, dos trabalhadores acidentados, somente $22 \%$ realizaram a notificação, enquanto que $78 \%$ dos trabalhadores não a realizaram.

Abstrai-se também que a ocorrência desse tipo de acidente não está relacionada apenas ao nível de formação, mas também ao treinamento, capacitação, recursos materiais disponíveis e cultura local. (MARZIALE, RODRIGUES, 2002).

Uma pesquisa realizada por Canini, et al. (2002) no ano de 1998, segundo a distribuição dos acidentes ocupacionais com materiais perfurocortantes ocorridos com trabalhadores de enfermagem em relação à categoria funcional, mostra que: 21,26\% acometem enfermeiros; 18,81\% acometem técnicos de enfermagem; 62,99\%, auxiliares de enfermagem e 3,94\%, atendentes de enfermagem.

Podemos verificar o alto índice de acometimento de auxiliares de enfermagem, sendo estes profissionais os que mais manipulam os materiais 
perfurocortantes e, portanto, são eles os responsáveis por seu descarte inadequado e pela maior exposição dos trabalhadores de outras categorias funcionais a esses riscos, principalmente funcionários da limpeza.

Segundo Canini et al. (2002), dos acidentes notificados ao Serviço Especializado em Engenharia de Segurança e Medicina do Trabalho (SESMT), $71 \%$ acometiam a equipe de enfermagem e 28,8\% atingiam outras categorias, entre pessoal da limpeza, manutenção, lavanderia, técnicos de laboratório, etc.

Os acidentes que envolvem as outras categorias incluem: agulhas e outros objetos perfurocortantes descartados em locais impróprios: leitos de paciente, mesa de cabeceira, bandeja de medicação, chão e o próprio lixo comum.

Evitar a exposição ocupacional é o principal caminho para prevenir a transmissão dos vírus da hepatite B e C e o vírus HIV. Entretanto, a imunização contra hepatite $\mathrm{B}$ e o atendimento adequado pós-exposição são componentes integrais para um programa completo de prevenção destas infecções e elementos importantes para a segurança do trabalho (SASSI, 204).

Deve-se também adequar as caixas de descarte de materiais perfurocortantes e treinar os trabalhadores da área da saúde a aderirem às precauções padrão.

Segundo Braga (2000), as precauções básicas foram instituídas com base no princípio de que todo paciente deve ser considerado como potencialmente infectado, independente do diagnóstico definido ou presumido de doença infecciosa. Tratam-se de medidas que devem ser utilizadas na manipulação de sangue, secreções e excreções, assim como no contato com mucosas e pele com áreas de integridade comprometida.

Incluem recomendações sobre o uso de equipamentos de proteção individual (luvas, gorros, óculos, capotes) com a finalidade de reduzir a exposição do trabalhador da saúde ao sangue ou fluído corpóreo, e cuidados específicos na manipulação e descarte de materiais perfurocortantes.

\section{Objetivos}

Caracterizar os acidentes com material biológico entre trabalhadores da equipe de saúde, segundo a categoria profissional, os elementos da equipe de enfermagem, a circunstância do acidente, o agente causal e o uso de equipamento de proteção individual.

\section{Metodologia}

\section{Tipo de estudo}

Trata-se de um estudo de levantamento de dados retrospectivo, com posterior análise estatística de percentagem, para obter as conclusões correspondentes aos dados levantados.
Segundo Gil (2002), o levantamento de dados recolhe informações de todos os integrantes do universo pesquisado, tendo-se um censo. São extremamente úteis, pois proporcionam informações gerais acerca das populações, que são indispensáveis em boa parte das investigações sociais.

\section{Local de investigação}

O local escolhido para o levantamento dos dados foi um SERVIÇO ESPECIAL DE SAÚDE, do interior do Estado de São Paulo. Esse serviço é responsável pela notificação e conduta dos casos de acidente de trabalho envolvendo material biológico, principalmente os perfurocortantes.

\section{População do estudo}

O estudo foi feito através de prontuários de notificação dos profissionais da saúde acidentados com exposição a material biológico, através de materiais perfurantes e cortantes ou exposição à mucosa, que procuraram o Serviço Especial de Saúde.

\section{Coleta de dados}

Foi elaborado um instrumento estruturado para a coleta dos dados, com posterior teste de adequação e coerência, visando atingir os objetivos propostos. Os dados foram coletados das notificações de janeiro a agosto de 2005 e obtevese um total de 113 notificações.

\section{Análise dos dados}

Foi realizada a análise estatística de percentagem correspondente aos dados levantados, com apresentações em quadros.

\section{Aspectos éticos}

Foi encaminhado para o Comitê de Ética do Centro Universitário de Araraquara (Uniara) para apreciação, sendo aprovado. Também foi solicitada a autorização para a coleta de dados pelo responsável do Serviço Especial de Saúde do interior do Estado de São Paulo.

\section{Resultados e discussão}

Foram analisados 113 acidentes, notificados no período de janeiro a agosto de 2005. Os dados obtidos mostraram que o sexo feminino foi predominante, já que a enfermagem é uma profissão de gênero feminino.

Pode-se observar no quadro 1 que a maioria dos acidentes acometeram o pessoal da enfermagem (58\%), e que, segundo os elementos da equipe de enfermagem (quadro 2), os auxiliares de enfermagem são os profissionais mais acometidos, com $60 \%$ do total de casos notificados. 
Quadro 1 - Acidentes ocupacionais notificados, segundo a categoria profissional. Araraquara, janeiro a agosto de 2005.

\begin{tabular}{|l|c|c|}
\hline Categoria Profissional & $\mathbf{n}^{\mathbf{0}}$ & $\mathbf{\%}$ \\
\hline Enfermagem & 65 & 58 \\
\hline Odontologia & 7 & 6 \\
\hline Laboratórios & 7 & 6 \\
\hline Estudantes & 10 & 9 \\
\hline Medicina & 2 & 2 \\
\hline Outras categorias & 22 & 19 \\
\hline Total & 113 & 100 \\
\hline
\end{tabular}

Fonte: Serviço Especial de Saúde do interior de SP.

Quadro 2 - Acidentes ocupacionais notificados, segundo os elementos da equipe de enfermage. Araraquara, janeiro a agosto de 2005.

\begin{tabular}{|l|c|c|}
\hline Elementos da Equipe de Enfermagem & $\mathbf{n}^{\mathbf{0}}$ & $\mathbf{\%}$ \\
\hline Enfermeiro & 2 & 3 \\
\hline Auxiliar de enfermagem & 39 & 60 \\
\hline Técnico de enfermagem & 24 & 37 \\
\hline Total & 65 & 100 \\
\hline
\end{tabular}

Fonte: Serviço Especial de Saúde do interior de SP.

Segundo Marziale e Rodrigues (2002), os auxiliares de enfermagem são os mais acometidos porque estão em contato direto com o paciente na maior parte do tempo, administrando medicamentos, realizando curativos e outros procedimentos que os mantém em constante contato com material perfurante e cortante.

Quando se analisam as diferentes categorias funcionais da enfermagem, vale a pena ressaltar que o fato dessa equipe ter membros com formação bastante heterogênea requer programas de educação em serviço, elaborados de maneira a contemplar essas diferenças (CANINI et al., 2002).

De acordo com a circunstância do acidente (quadro 3), pudemos observar que a maioria dos acidentes ocorreu quando os profissionais estavam administrando medicações (13\%), seguindo-se pelo descarte inadequado do material em bancada, cama, chão, etc. (11\%), pela realização de punções (10\%) e dextro (9\%).
Quadro 3 - Acidentes ocupacionais notificados, segundo a circunstância do acidente. Araraquara, janeiro a agosto de 2005.

\begin{tabular}{|l|c|c|}
\hline Circunstância do Acidente & $\mathbf{n}^{\mathbf{0}}$ & $\mathbf{\%}$ \\
\hline Adm. medicação & 15 & 13 \\
\hline Reencape de agulha & 6 & 5 \\
\hline Dextro & 10 & 9 \\
\hline Punção & 11 & 10 \\
\hline Descarte inadequado em saco de lixo & 2 & 2 \\
\hline Descarte inadequado em bancada, chão, cama, etc. & 12 & 11 \\
\hline Perfuração ou manipulação de caixas de descarte & 1 & 1 \\
\hline Lavagem do material & 5 & 4 \\
\hline Procedimento cirúrgico & 8 & 7 \\
\hline Procedimento odontológico & 7 & 6 \\
\hline Procedimento laboratorial & 4 & 4 \\
\hline Lavanderia & 2 & 2 \\
\hline Outros & 30 & 26 \\
\hline Total & 113 & 100 \\
\hline
\end{tabular}

Fonte: Serviço Especial de Saúde do interior de SP.

Grande parte das atividades dos trabalhadores de enfermagem está concentrada na administração de medicamentos, que envolvem a manipulação constante de agulhas e escalpes, sendo situações que mais expõem os trabalhadores ao risco de acidentes perfurocortantes (CANINI et al., 2002)

Portanto, os casos envolvendo o agente causal "agulha com luz" se sobressai nas notificações, com 53\% dos casos notificados, observados pelo quadro 4.

Quadro 4 - Acidentes ocupacionais notificados, segundo o agente causal. Araraquara, janeiro a agosto de 2005.

\begin{tabular}{|l|c|c|}
\hline Agente & $\mathbf{n}^{\mathbf{0}}$ & $\mathbf{\%}$ \\
\hline Agulha com luz & 60 & 53 \\
\hline Agulha sem luz & 12 & 11 \\
\hline Intracath & 1 & 1 \\
\hline Vidro & 4 & 3 \\
\hline Lâmina/lanceta & 9 & 8 \\
\hline Outros & 17 & 15 \\
\hline Ignorado & 10 & 9 \\
\hline Total & 113 & 100 \\
\hline
\end{tabular}

Fonte: Serviço Especial de Saúde do interior de SP. 
Segundo o uso de EPI(quadro 5), observa-se que somente 41\% das notificações apresentaram o uso das luvas. Fato preocupante, visto que o uso de luvas, juntamente com o uso dos outros EPI, foram instituídos com o intuito de reduzir a exposição do trabalhador da saúde ao sangue ou fluídos corpóreos (BRAGA, 2000).

Quadro 5 - Acidentes ocupacionais notificados, segundo o uso de EPI. Araraquara, janeiro a agosto de 2005.

\begin{tabular}{|l|c|c|}
\hline EPI & $\mathbf{N}^{\mathbf{0}}$ & $\mathbf{\%}$ \\
\hline Luvas & 74 & 41 \\
\hline Óculos & 16 & 9 \\
\hline Máscara & 22 & 12 \\
\hline Avental & 38 & 21 \\
\hline Bota & 2 & 1 \\
\hline Nenhum & 30 & 16 \\
\hline Total & 182 & 100 \\
\hline
\end{tabular}

Fonte: Serviço Especial de Saúde do interior de SP.

Frente a esses resultados, torna-se evidente a necessidade de se realizar um treinamento, principalmente do pessoal da enfermagem, em relação aos riscos de acidentes ocupacionais. Deve-se também buscar alternativas que possam conferir maior segurança aos trabalhadores, como aderir às precauções padrão, realizar os procedimentos com segurança, utilizar adequadamente os EPIs, evitar manipulação desnecessária de material perfurocortante e material biológico, além de ter a responsabilidade de realizar a notificação do acidente no momento em que este ocorre (SASSI, 2004).

\section{Considerações finais}

Os resultados obtidos através desta pesquisa permitem as seguintes considerações: o número de notificações tem aumentado nos últimos anos, visto que, desde janeiro a agosto de 2005, foram notificados 113 casos. Esses números, comparados com os do ano inteiro de 2004, com 154 notificações, mostra-nos um aumento significativo.

Sabe-se que os maiores riscos dos acidentes não são as lesões, mas os agentes biológicos veiculados pelo sangue e secreções corporais, principalmente o HIV e o HBV, que estão presentes nos objetos causadores.

A análise dos dados permitiu verificar que todas as categorias profissionais da saúde estão sujeitas aos acidentes de trabalho, e que a categoria mais atingida é o da enfermagem, principalmente os auxiliares de enfermagem.
A circunstância em que mais ocorre acidente é na administração de medicação, portanto, o profissional necessita de maior treinamento e capacitação, visto que as agulhas com luz são os principais agentes causais.

Os profissionais precisam se adequar mais às precauções básicas e aderirem ao uso dos equipamentos de proteção individual (EPI), que reduzem a exposição do trabalhador ao sangue e fluídos corpóreos.

\section{Referências:}

BRAGA, D. Acidente de trabalho com material biológico em trabalhadores da equipe de enfermagem do centro de pesquisas Hospital Evandro Chagas. 2000. 75p. Dissertação de Mestrado. Fundação Oswaldo Cruz, Escola Nacional de Saúde Pública, 2000.

BREVIDELLI, M.M.; CIANCIARULHO, T.I. Aplicação do modelo de crenças em saúde na prevenção dos acidentes com agulha. Revista Saúde Pública, São Paulo, v.35, n.2, p.193-201, 2001.

CANINI, S.R.M.S.; GIR, E.; HAYASHIDA, M.; MACHADO, A.A. Acidentes perfurocortantes entre trabalhadores de enfermagem de um hospital universitário do interior paulista. Revista Latino-Americana de Enfermagem, Ribeirão Preto, v.10, n.2, p.172-178, mar./abr. 2002.

GIL, A.C. Como elaborar projetos de pesquisa. 4. ed. São Paulo: Atlas, 2002. 50p.

MARZIALE, M.H.P.; RODRIGUES, C.M. A produção científica sobres os acidentes de trabalho com material perfurocortante entre trabalhadores de enfermagem. Revista Latino-Americana de Enfermagem, Ribeirão Preto, v.10, n.4, p.571-7, jul./ago. 2002.

MARINHO, J. et al. Atenção aos perigos biológicos no trabalho. Revista COREN SP, São Paulo, n.57, p.6-7, mai./jun. 2005.

MARINHO, J. et al. Profissão Perigo. Revista COREN SP, São Paulo, n.52, p.7-11, jul./ago. 2004.

REZENDE, M.P. Agravos à saúde de auxiliares de enfermagem resultantes da exposição ocupacional aos riscos físicos - Ribeirão Preto, 2003. Dissertação de Mestrado. Escola de Enfermagem, Universidade de São Paulo, Ribeirão Preto, 2003. 
SASSI, S.J.G. Acidente com material biológico: o que há em prevenção.

Boletim Epidemiológico, São Paulo, ano II, n.1, p.3-7, jan. 2004.

\section{Resumo:}

O presente estudo, de caráter retrospectivo, realizado em um Serviço Especial de Saúde, objetivou caracterizar os acidentes com material biológico entre a equipe de saúde. Os resultados evidenciaram que, das 113 notificações, 58\% acometeram os trabalhadores da enfermagem. As situações mais freqüentes de ocorrência se deram na administração de medicamentos (13\%) e, tratando-se do agente causal, a agulha com luz se sobressaiu com 53\%. Ressalta-se que somente $41 \%$ dos profissionais utilizavam luvas.

\section{Palavras-chave:}

Riscos Ocupacionais, Equipe de Enfermagem, Biossegurança. 